\title{
Astaxanthin level of dominant mangrove floral species in Indian sundarbans
}

\begin{abstract}
The astaxanthin level in the leaves of five dominant mangrove species, sampled from two different stations of Sager Island in western Indian Sundarbans region was studied during April, 2016. The two sampling stations selected at the northern and southern tips of the island exhibited drastic variation with respect to aquatic salinity, although other parameters like surface water temperature, $\mathrm{pH}$, D.O. and nutrients were more or less uniform. Relatively higher astaxanthin level was observed in the high saline zone (southern tip) of the island, which indicates the regulation of astaxanthin level in the mangrove plants by ambient aquatic salinity. The inundated leaves of the selected mangrove plants showed more astaxanthin level in comparison to the exposed ones. The astaxanthin content of the mangrove leaves was in the order Heritiera fomes $>$ Avicennia alba $>$ Avicennia marina $>$ Avicennia officinalis $>$ Sonneratia apetala in both the sampling stations which points towards the species specificity of the carotenoid pigment.
\end{abstract}

Volume I Issue 2 - 2017

\author{
Kakoli Banerjee,' Goutam Roy Chowdhury, \\ Abhijit Mitra ${ }^{3}$ \\ 'School of Biodiversity \& Conservation of Natural Resources, \\ Central University of Orissa, India \\ ${ }^{2}$ Chancellor, Techno India University, India \\ ${ }^{3}$ Department of Marine Science, University of Calcutta, India
}

Correspondence: Abhijit Mitra, Department of Marine Science, University of Calcutta, 35 B. C. Road, Kolkata 700019 , India,Tel 983।269550,Email abhijit_mitra@hotmail.com

Received: April 25, 2016 | Published: May 03, 2017

Keywords: mangroves, astaxanthin, Indian sundarbans, tidal influx, salinity gradient

\section{Introduction}

Astaxanthin (Figure 1) is the main carotenoid pigment found in microorganisms (the yeast Phaffia rhodozyma and the algae Haematococcus pluvialis), ${ }^{1}$ aquatic animals and many of the seafood including salmon, trout, red sea bream, shrimp, lobster and fish eggs. It is also present in birds such as flamingoes and quails. ${ }^{2}$ Availability of astaxanthin has also been reported in mangrove flora, ${ }^{3}$ under different tidal conditions. ${ }^{4}$

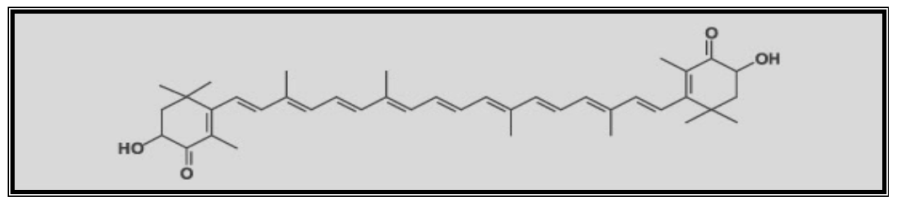

Figure I Structure of Astaxanthin.

The mangroves of Indian Sundarbans, being a reservoir of several bioactive substances ${ }^{5}$ may serve as future source of astaxanthin, although very few works have been carried out on this particular subject. Astaxanthin has several essential biological functions in animals $^{6}$ and is known as a free radical quencher and powerful antioxidative reagent. ${ }^{7}$ Industrially, astaxanthin has been commercially exploited as a pigmentation source and feed supplement for marine fish aquaculture and poultry. It is evident, therefore, that astaxanthin is a molecule with potential to the pharmaceutical, food, cosmetic and medical fields.

The industrial production of astaxanthin has been successful in many parts of the world through series of chemical reactions, but the synthetic type is not similar to that found in nature as its stability and activity is lower than that of natural product. Therefore attention has been diverted for searching the natural source of astaxanthin. The deltaic complex of Indian Sundarbans at the apex of the Bay of Bengal $\left(21^{\circ} 13^{\prime}\right.$ to $22^{\circ} 40^{\prime} \mathrm{N}$ latitude and $88^{\circ} 03^{\prime}$ to $89^{\circ} 07^{\prime}$ E longitude) sustains 34 species of true mangroves, ${ }^{8}$ which are specialized floral community found at the land-sea interface in the estuarine and coastal ecosystems (Figure 2).

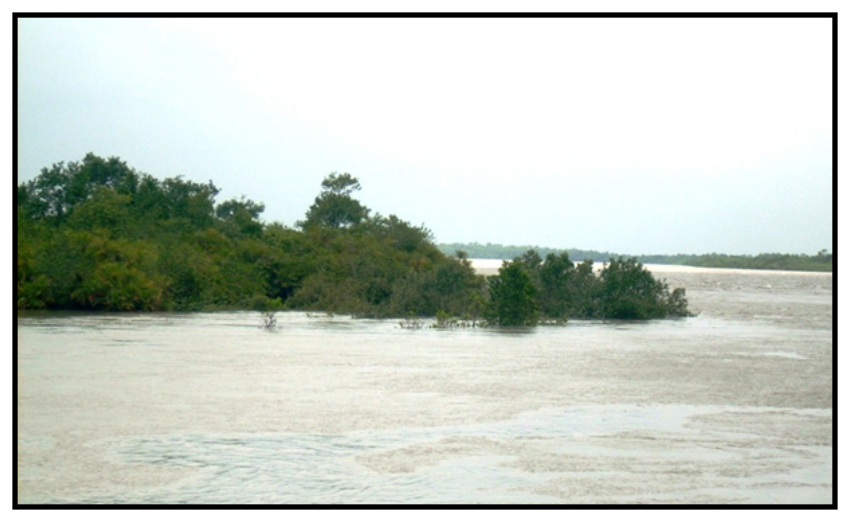

Figure 2 Mangroves: A special types of halophytes found at the land-sea interface.

These plants are characterized with the presence of pnematophores, prop roots, stilt roots and viviparous germination and are exposed to tidal inundations twice in every 24 hours in this part of the Indian subcontinent. ${ }^{9}$ The important ecological requisites for the growth of these plants are water salinity (ranging from $2 \%_{0}$ to $30 \%_{0}$ ), $\mathrm{pH}$ (around 8.00 ), tidal inundation and clayey-cum-silty soil substratum typical for deltaic complex. Considering the immense ecological and economic benefits of these plants, ${ }^{10}$ the Govt. of India (Ministry of Environment and Forests) has taken up several programmes of afforestation and nursery development ${ }^{11}$ in and around Indian Sundarbans and hence proper back-up of raw materials exists in this region that can serve as natural source of astaxanthin.

\section{Materials and methods}

Sagar Island is the largest island of Indian Sundarbans (located between $21^{\circ} 31^{\prime} \mathrm{N}$ to $21^{\circ} 53^{\prime} \mathrm{N}$ latitude and $88^{\circ} 02^{\prime} \mathrm{E}$ to $88^{\circ} 15^{\prime} \mathrm{E}$ meredians) with an approximate area of 145 sq. km. The entire network of the present programme consists of the sampling of five dominant mangrove species from the northern and southern tips of Sagar Island during April, 2016. These two sampling stations are drastically 
different from each other with respect to salinity as the northern tip of the island lies within the Hugli estuarine stretch, whereas the southern tip is located at the confluence of the river Hugli and the Bay of Bengal. Leaves of the selected species were collected during the low tide period from two different portions (submerged lower zone and exposed upper zone) of the same plant. The lower region of the tree is inundated during the high tide condition and the upper region of the same plant remains unexposed to tidal water. The collected leaves were thoroughly washed with ambient water followed with deionized water and oven dried at $110^{\circ} \mathrm{C}$ overnight. The estimation of carotenoid were separately carried out for each species through spectrophotometric method after extraction with DMSO and acetone and finally the carotenoid value was converted to astaxanthin percent as per the expression: Percent astaxanthin=Carotenoids $(\mathrm{mg})$ extracted/ sample weight $(\mathrm{mg}) \times 80$.

Water samples of both the stations were also collected simultaneously for analyzing the physico-chemical variables (surface water temperature, salinity, $\mathrm{pH}, \mathrm{DO}$, nitrate, phosphate and silicate) as per the standard methods. ${ }^{12}$

\section{Results and discussion}

The astaxanthin level in the selected mangrove species exhibits significant spatial variation (Table 1).

Table I Astaxanthin content in five mangrove species collected from two different stations of Sagar Island, Sundarbans during April 20 I6

\begin{tabular}{|c|c|c|c|}
\hline \multirow{2}{*}{ Station } & \multirow{2}{*}{ Mangrove species } & \multicolumn{2}{|c|}{ Astaxanthin content ( $\mathrm{mg} / \mathrm{kg})$} \\
\hline & & Submerged & Exposed \\
\hline \multirow{5}{*}{$\begin{array}{l}\text { Kachuberia } \\
\text { (salinity range: I\%॰ to } 9 \% \circ \text { ) }\end{array}$} & Avicennia alba & 485.08 & 313.02 \\
\hline & Avicennia marina & 409.66 & 298.73 \\
\hline & Avicennia officinalis & 388.02 & 267.44 \\
\hline & Sonneratia apetala & 156.14 & 94.32 \\
\hline & Heritiera fomes & 619.20 & 386.25 \\
\hline \multirow{5}{*}{$\begin{array}{l}\text { Sagar south } \\
\text { (salinity range: I } 2 \% \circ \text { to } 28 \% \circ \text { ) }\end{array}$} & Avicennia alba & 513.95 & 353.20 \\
\hline & Avicennia marina & 449.36 & 340.13 \\
\hline & Avicennia officinalis & 420.10 & 310.41 \\
\hline & Sonneratia apetala & 225.21 & 130.42 \\
\hline & Heritiera fomes & 680.22 & 391.02 \\
\hline
\end{tabular}

The two sampling stations in the present programme are drastically different with respect to surface water salinity although other parameters are more or less uniform (Table 2).

Table 2 Physico-chemical variables of water samples collected from two different stations of Sagar Island, Sundarbans during April, 2016

\begin{tabular}{lll}
\hline Parameters & Northern tip & Southern tip \\
\hline Surface water temp $\left({ }^{\circ} \mathrm{C}\right)$ & $33.0 \pm 0.02$ & $33.2 \pm 0.0 \mathrm{I}$ \\
$\mathrm{pH}$ & $8.00 \pm 0.0 \mathrm{I}$ & $8.21 \pm 0.0 \mathrm{I}$ \\
Salinity $(\mathrm{psu})$ & $8.50 \pm 0.3 \mathrm{I}$ & $27.23 \pm 0.44$ \\
$\mathrm{DO}(\mathrm{mg} / \mathrm{l})$ & $5.82 \pm 0.23$ & $6.01 \pm 0.19$ \\
$\mathrm{NO}_{3}(\mu \mathrm{gat} / \mathrm{l})$ & $15.32 \pm 0.3 \mathrm{I}$ & $16.26 \pm 0.39$ \\
$\mathrm{PO}_{4}(\mu \mathrm{gat} / \mathrm{l})$ & $1.72 \pm 0.05$ & $1.45 \pm 0.04$ \\
$\mathrm{SiO}_{3}(\mu \mathrm{gat} / \mathrm{l})$ & $85.90 \pm \mathrm{I} .07$ & $91.24 \pm 0.98$ \\
\hline
\end{tabular}

The proximity of the southern tip of Sagar Island to Bay of Bengal may be attributed to high aquatic salinity in this zone. The relatively higher astaxanthin level in the plant parts collected from the southern tip of Sagar Island may be related to stress posed by high aquatic salinity. Similar variations of the pigment level with geographic location have been pointed out by several workers. ${ }^{13}$ In both the sampling stations, a uniformity was observed with respect to astaxanthin level of the mangrove leaves and it is in the order Heritiera fomes $>$ Avicennia alba $>$ Avicennia marina $>$ Avicennia officinalis $>$ Sonneratia apetala (Table 1). Astaxanthin occurs in several different forms and can be classified into stereoisomer's, geometric isomers and free or esterified forms. All these forms are found in various natural sources e.g., the predominant stereoisomers of astaxanthin found in the Antarctic krill Euphausia superba is $3 \mathrm{R}, 3 \mathrm{R}$ and the majority of this is esterified. ${ }^{14-18}$ The relative distribution of esters and optical isomers in some organisms is shown in Table 3. The level of astaxanthin detected in the mangrove floral species of Indian Sundarbans is less than the existing natural mega-reservoir of astaxanthin like Phaffia rhodozyma, ${ }^{19}$ Whyte $^{20}$ and Haematococcus pluvialis. ${ }^{21}$ However considering the huge biomass of mangrove leaves in and around the area of Sundarban Biosphere Reserve (SBR), the standing stock of the carotenoid pigment has high probability to reach the point of compensation (requirement), provided few back-up nurseries in the region for extraction of bioactive substances are maintained.

The relatively higher astaxanthin content in the submerged leaves of mangrove plants confirms the synthesis of the pigment under stressful condition. However, more studies are needed to establish the role of tidal influx and subsequent salinity fluctuation of the ambient aquatic phase on astaxanthin level in the mangrove floral parts. The present data may serve as baseline information on the regulatory role of tidal submergence on astaxanthin level in the estuarine and coastal vegetation. The enhancement of astaxanthin production under stressed condition of organisms is a matter of interest and several researches are still being undertaken to pinpoint the reaction pathway of astaxanthin production by inducing stress of varied nature. Many yeasts have been described with an increase ability to produce carotenoids when they grow under unfavorable environment. ${ }^{22}$ The enhancement of the accumulation of astaxanthin in cysts of Haematococcus pluvialis 
under salt stress conditions has been reported both in the dark and light by several workers. ${ }^{23-31}$ The present study has pointed higher astaxanthin level in those leaves of the mangroves that are inundated for 10 to 12 hours by tidal waters (ambient water salinity during the period of investigation was $8.50 \%$ in the northern tip of Sagar Island and $27.23 \%$ in the southern tip of Sagar island) thus exposed to stress caused by aquatic salinity. The steep enhancement of astaxanthin level in the inundated Sundari leaves (Heritiera fomes) irrespective of the sampling stations (space) clearly reflects the highest degree of stress posed by water salinity on this species. Heritiera fomes, being fresh water loving mangrove species cannot tolerate high salinity ${ }^{32}$ and hence acceleration of astaxanthin production may probably be a part of its adaptation to cope with the stenohaline condition of coastal and estuarine environment that becomes acute during high tide. The astaxanthin level of mangrove flora is thus a function of its physiological system, which is extremely species specific.

Table 3 Free and esterified astaxanthin and ratio of optical isomers (RR':RS':SS') in some crustaceans, the yeast Phaffia rhodozyma and Haematococcus pluvialis*

\begin{tabular}{llllll}
\hline Astaxanthin & Free & Diester & Monoester & Ratio optical isomers \\
\cline { 6 - 6 } & & & & RR/: RS/ : SS/ \\
\hline Euphausia superba (Antarctic krill) & 5 & 64 & 31 & $9: 21: 70$ \\
Thysanoessa inermis (Antarctic krill) & 4 & 61 & 35 & $55: 07: 38$ \\
Calanus finmarchicus (Marine copepode) & 11 & 46 & 43 & $83: 03: 14$ \\
Acanthephyra purpurea (Deep sea shrimp) & 20 & 43 & 37 & $20: 44: 15$ \\
Cancer pagurus shell (Edible crab shell) & 58 & 22 & 13 & $20: 24: 56$ \\
Phaffia rhodozyma (Red yeast) & 100 & & & $98:+:+$ \\
Haematococcus pluvialis (Alga) & 5 & 59 & 22 & $4: 8: 88$ \\
\hline
\end{tabular}

*The free and esterified astaxanthin and ratio of optical isomers is based on refs 15-18.

In both plant and animal kingdoms, the protective role of astaxanthin to tide over unfavorable environmental conditions is very prominent. This carotenoid pigment plays many important functions in fishes, crustaceans and several aquatic animals like improved protection against oxidation and photo-oxidation, reproduction and development, immune response, resistance to diseases and communication system. Recent research shows that astaxanthin acts like a vitamin for salmon. Now-a-day astaxanthin is used as a source of pigmentation for fish in aquaculture and for eggs in the poultry industry. ${ }^{33}$ It also recognized as having a higher antioxidant activity than other carotenoids, ${ }^{34,35}$ Kobayashi $^{36}$ and hence has a great role to play in the sector of aqua cultural feed and poultry feed production. The present research has immense relevance in the framework of Indian Sundarbans as several small scale mangrove based astaxanthin industries like cattle feed, fish feed, poultry feed units can be set up involving the local people.

This will not only improve the quality of products, but can bind substantial number of island dwellers in the matrix of alternative livelihood schemes, who otherwise are engaged in illegal intrusion in the mangrove forest for exploitation of natural resources, poaching of wild animals, honey collection, prawn seed collection and several anti-conservation related activities.

\section{Acknowledgements}

This research is a part of GRC Vision 2025 programme, which is the brain child of Chancellor, TIU to eradicate poverty, over population and pollution initially at local scale and then at regional and global scales. The road map for this programme includes the promotion of Green technology, Agri-Biotechnology, Hydroponics, Zero Emission transportation and low cost fly ash based structures and propagating the same through special Franchise Model developed by Prof. Sujoy Biswas, CEO of TIU, and West Bengal.

\section{Conflict of interest}

The author declares no conflict of interest

\section{References}

1. Johnson EA, An GH. Astaxanthin from microbial sources. Crit Rev Biotechnol. 1991;11(4):297-326.

2. Certik M, Masrnova S, Sitkey V, et al. Biotechnological production of astaxanthin Chem. Listy. 2005;99:s237-s240.

3. Abhiji M, Banerjee K, Banerjee A. Screening mangroves in search of astaxanthin. Seshaiyana. 2006;14(1):1-2.

4. Abhijit M, Shibdas B, Banerjee K, et al. Impact of tidal submergence on astaxanthin content of mangroves. Ultra Scientist of Physical Sciences. 2006;18(2):117-122.

5. Chaudhuri AB, Choudhury A. In Mangroves of the Sundarbans. India: IUCN; 1994. 247 p.

6. Guerin M, Huntley M, Olaizola M. Haematococcus astaxanthin: applications for human health and nutrition. Trends Biotechnol. $2003 ; 21(5): 210-216$

7. Naguib YJ. Antioxidant activities of astaxanthin and related carotenoids. J Agric Food Chem. 2000;48(4):1150-1154

8. Mitra A. The north-west coast of the Bay of Bengal and deltaic Sundarbans. In Seas at the Millennium: An Environmental Evaluation. 2000;2:145-160.

9. Mitra A, Banerjee K, Bhattacharyya DP. In The Other Face of Mangroves. Dept of Environment Govt. of W.B; 2004. 132 p.

10. Banerjee K, Abhijit M. Mangroves and Mangals-Ecological and Economic Valuation. Journal of Indian Ocean Studies. 2004;12(1):132144.

11. Abhijit M, Banerjee K. In Living Resources of the Sea: Focus Indian Sundarbans. New Delhi: WWF-India Secretariat, Sunderbans Landscape Project; 2005. 120 p

12. Strickland JDH, Parsons TR. In A practical handbook of seawater analysis. Fish Res Board Can Ottawa. 1972;44(3):310.

13. Gilchrist BM, Lee WL. Carotenoid pigments and their role in reproduction in the sand crab Emerita analoga (Stimpson, 1857). Comp Biochem Physiol. 1972;42(2):B263-B294. 
14. Bernhard K. Synthetic astaxanthin. The route of a carotenoid from research to commercialization. In Carotenoids: Chemistry and Biology. In: Krinsky NI, et al. editors. Plenum Press; 1990. p. 337-363.

15. Foss $P$, Renstrom B, Liaaen-Jensen S. Natural occurrence of enantiomeric and meso astaxanthin 7-crustaceans including zooplankton. Comp Biochem Physiol. 1987;86B(2):313-314.

16. Grung M, Dsouza FML, Borowitzka M, et al. Algal carotenoids 51. Secondary carotenoids 2 . Haematococcus pluvialis as a source of (3S 3/S)-astaxanthin esters. J Applied Phycology. 1992;4(2):165-171.

17. Muller RK, Bernhard K, Mayer H, et al. Beitrag zur analytic und synthese von 3-hydroxy-4-oxocarotinoiden. Helv Chim Acta. 1980;63(6):16541664 .

18. Bowen J, Soutar C, Serwata RD, et al. Utilization of (3S, 3/S)-astaxanthin acyl esters in pigmentation of rainbow trout (Oncorhynchus mykiss). Aquaculture Nutrition. 2002;8(1):59-68.

19. Johnson EA, Conklin DE, Lewis MJ. The yeast Phaffia rhodozyma as a dietary pigment source for salmonids and crustaceans. J Fish Res Board Canada. 1977;34(12):2417-2421.

20. Whyte JNC, Sherry KL. Pigmentation and composition of flesh of Atlantic salmon fed diets supplemented with the yeast Phaffia rhodozyma. $N A m$ J Aquacult. 2001;63(1):52-57.

21. Sommer TR, Potts WT, Morrissy NM. Utilization of microalgal astaxanthin by rainbow trout (Oncorhynchus mykiss). Aquaculture. 1991;94(1):79-88

22. Certik M, Breierova E. Chem Listy. 2002;96:147.

23. Kobayashi M, Kurimura Y, Tsuji Y. Light independent astaxanthin production by the green microalga Haematococcus pluviallis under salt stress. Biotechnology Letters. 1997;19(6):507-509.

24. Spencer KG. Pigmentation supplements for animal feed compositions. US patent No 4. 1989;871:551.

25. Borowitzka MA, Huisman JM, Osborn A. Culture of astaxanthin producing green alga Haematococcus pluvialis I. Effects of nutrients on growth and cell type. J Appl Phycol. 1991;3(4):295-304.
26. Boussiba S, Vonshak A. Astaxanthin accumulation in the green alga Haematococcus pluvialis 1. Plant Cell Physiol. 1991;32:1077-1082.

27. Boussiba S, Fan L, Vonshak A. Enhancement and determination of astaxanthin accumulation in green alga Haematococcus pluvialis. Methods in Enzymology. 1992;213C:386-391.

28. Cordero B, Otero A, Patino M, et al. Astaxanthin production from the green alga Haematococcus pluvialis with different stress conditions. Biotechnology Letters. 1996;18:213-218.

29. Harker M, Tsavalos AJ, Young AJ. Use of response surface methodology to optimize carotenogenesis in the microalga Haematococcus pluvialis. $J$ Appl Phycol. 1995;7(4):399-406.

30. Harker M, Tsavalos AJ, Young AJ. Autotrophic growth and carotenoid production of Haematococcus pluvialis in a 30 liter air-lift photobioreactor. J Ferment Bio eng. 1996;82:101-106.

31. Harker M, Tsavalos AJ, Young AJ. Factors responsible for astaxanthin formation in the chlorophyte Haematococcus pluvialis. Bioresource Technology. 1996;55(3):207-241.

32. Mitra A, Pal S. The oscillating mangrove ecosystem and the Indian Sundarbans. In: Shakti Banerjee, Farida Tampal, editors. India: WWF, WBSO; 2002. 108 p.

33. Cifuentes AS, Gonzalez MA, Vargas S, et al. Optimization of biomass, total carotenoids and astaxanthin production in Haematococcus pluvialis Flotow strain Steptoe (Nevada, USA) under laboratory conditions. Biol Res. 2003;36(3-4):343-357.

34. Meyers SP. Developments in world aquaculture, feed formulations and role of carotenoids. Pure Appl Chem. 1994;66(5):1069-1076.

35. Miki W. Biological functions and activities of animal carotenoids. Pure Appl Chem. 1991;63(1):141-146.

36. Kobayashi M, Kakizono T, Nishio N, et al. Antioxidant role of astaxanthin in the green alga Haematococcus pluvialis. Appl Microbiol Biotechnol. $1997 ; 48(3): 351-356$ 